\title{
AC Magnetic Properties of Vitroperm Based Composite Materials
}

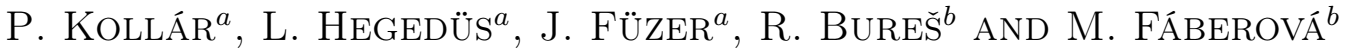

${ }^{a}$ Institute of Physics, Faculty of Science, P.J. Šafárik University, Park Angelinum 9, 04154 Košice, Slovakia

${ }^{b}$ Institute of Materials Research, Slovak Academy of Sciences, Watsonova 47, 04001 Košice, Slovakia

The aim of this work was to investigate the influence of resin content on AC magnetic properties of Vitroperm 800-based composite material to extend possibilities for application of this kind of material at higher frequency (up to $100 \mathrm{kHz}$ ). The samples of composite material were prepared in the form of the ring with outer diameter of $25 \mathrm{~mm}$, inner diameter of $18 \mathrm{~mm}$ and height approximately $3 \mathrm{~mm}$. Powder mixtures were prepared from Vitroperm 800 in partial nanocrystalline state and commercial termoset resins by mechanical mixing. The AC magnetic properties (losses) at maximum induction up to $0.5 \mathrm{~T}$ were measured by MATS-2010SA loop tracer in frequency range $1-100 \mathrm{kHz}$. The specific resistivity of the material was measured by the van der Pauw method. The magnetic properties of the composite rings were compared with the properties of the material prepared from Fe based powder supported by Höganäs. It was found out that the total losses of the Vitroperm-based soft magnetic composite are more than 10 times lower (at $10 \mathrm{kHz}$ ) than that for Fe-based one.
\end{abstract}

PACS numbers: 75.50.Tt, 81.05.Ni, 85.70.-w, 75.60.-d, 75.50.Bb

\section{Introduction}

Soft magnetic composite (SMC) is well known group of materials for applications as cores (in transformers, electromotors and electromagnetic circuits, sensors, electromagnetic actuation devices, low frequency filters, induction field coils, magnetic seal systems and magnetic field shielding) with three dimensional isotropic ferromagnetic behaviour with the possibility to replace in some applications instead of electrical steel sheets or ferrites [1].

In the SMC ferromagnetic powder particles are surrounded by an electrical insulating film and often exhibit very good soft magnetic properties as low hysteresis losses, low eddy current losses, high permeability at low magnetic field and high saturation flux density [2-4]. Many scientists think that the magnetic properties of SMC can be still improved by selection of the suitable ferromagnetic material, insulating material and fabrication process.

The aim of this work was to analyze the influence of resin content on $\mathrm{AC}$ magnetic properties in frequency range from $1 \mathrm{kHz}$ to $100 \mathrm{kHz}$ of Vitroperm 800 $\left(\mathrm{Fe}_{73} \mathrm{Cu}_{1} \mathrm{Nb}_{3} \mathrm{Si}_{16} \mathrm{~B}_{7}\right)$ based SMC.

\section{Sample preparation and experimental}

The SMC samples were prepared by conventional powder metallurgy in form of a ring (for magnetic measurements) and in form of a cylinder (for electric resistivity measurements). The Vitroperm 800 [5] was chosen as an excellent soft magnetic ferromagnetic material and a phenol-formaldehyde resin (Bakelite ATM) as insulator.
The flakes of Vitroperm, supported by Vacuumschmelze, are $400 \mu \mathrm{m}$ large in diameter (mean value) and $20 \mu \mathrm{m}$ thick, Fig. 1a. The structure of the Vitroperm flakes was checked by XRD diffraction (RTG Diffractometer type, Philips XPERT PRO) to be in amorphous, partially nanocrystalline state.

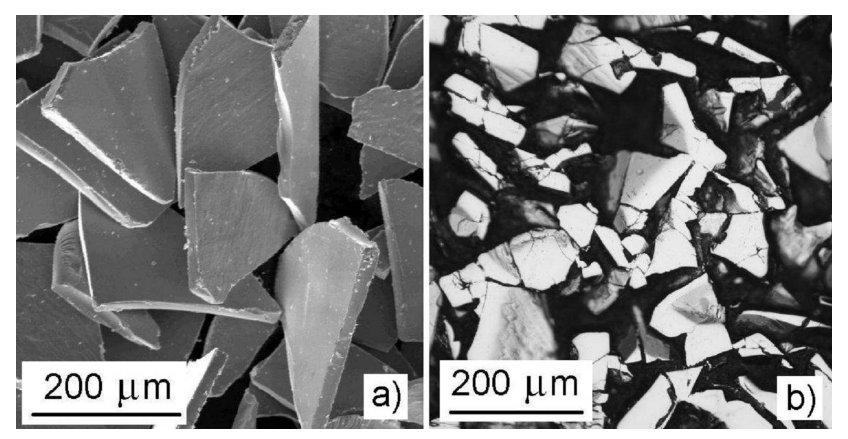

Fig. 1. (a) The Vitroperm flakes before consolidation, (b) broken flakes after consolidation of sample 5 observed by transmission electron microscopy (TEM).

The morphology of the flakes was investigated by scanning electron microscopy (TESLA BS 340) and microstructure of the compact was analysed by the optical microscope Olympus GX71.

The bakelite was milled for $3 \times 30 \mathrm{~s}$ in a knife mill to obtain the particle size below $100 \mu \mathrm{m}$. The experimental samples were prepared by wet homogenisation of Vitroperm flakes and resin 5 vol.\% for sample 5 and 10 vol.\% for sample 10 with acetone. 
The homogenised powder was pressed in a cylindrical die at uniaxial pressure to obtain compacts in the form of cylinder or ring. The Vitroperm flakes were during consolidation process broken down to several smaller pieces, Fig. 1b.

After that the resulting product was cured at a temperature of $180^{\circ} \mathrm{C}$ for $60 \mathrm{~min}$ in an electric furnace in air atmosphere.

The thermoset phenol-formaldehyde resin covers the iron powder particles, the resin electrically insulates conductive iron particles and creates the mechanical bond after curing, Fig. $1 \mathrm{~b}$.

Sample $S$ is a reference material, prepared from Somaloy ${ }^{\circledR} 700$ powder (with mean value of the powder particle diameter of $120 \mu \mathrm{m}$ covered by insulating film) provided by Höganäs AB, Sweden [6] by producer-developed technology (compaction at $800 \mathrm{MPa}$ and heat treatment at $530^{\circ} \mathrm{C}$ for $30 \mathrm{~min}$ in air) [7]. Parameters of the samples are in Table.

TABLE

Parameters of the samples.

\begin{tabular}{l|c|c|c}
\hline \hline \multicolumn{1}{c|}{ Sample } & 5 & 10 & $S$ \\
\hline vol. fraction of ferromagnet [\%] & 95 & 90 & 98.7 \\
outer diameter [mm] & 24.28 & 24.22 & 24.10 \\
inner diameter [mm] & 17.74 & 17.71 & 17.71 \\
height [mm] & 2.72 & 2.75 & 2.81 \\
mass [g] & 2.822 & 2.681 & 3.870 \\
density [g/cm ${ }^{3}$ ] & 4.82 & 4.60 & 6.57 \\
compaction pressure $[\mathrm{MPa}]$ & 800 & 800 & 800 \\
compaction temperature $\left[{ }^{\circ} \mathrm{C}\right]$ & 180 & 180 & 530 \\
porosity [\%] & 31 & 32 & 12.4 \\
specific resistivity $[\mu \Omega \mathrm{m}]$ & 750 & 830 & 4.58
\end{tabular}

The hysteresis loss were calculated from the DC hysteresis loops measured by a fluxmeter based hysteresisgraph. The AC hysteresis loops were measured in the frequency range $1-100 \mathrm{kHz}$ by AC hysteresisgraph MATS-2010SA at the maximum flux density of $0.05,0.1,0.2$, $0.3,0.4$ and $0.5 \mathrm{~T}$. The total losses were calculated directly from measured hysteresis loops.

The specific electrical resistivity of the composite material in the form of the cylinder with diameter of about $10 \mathrm{~mm}$ and approximately $2 \mathrm{~mm}$ height was measured by the van der Pauw method (assuming to be isotropic in the plane parallel to the cylinder base) [8].

\section{Results}

The values of total losses as a function of maximum flux density increase similarly for sample 5 and sample 10 with the same tendency as for reference sample $S$, only the values are smaller, Fig. 2. The lower values of losses of the samples 5 and 10 are caused by lower contribution of the hysteresis losses $W_{\mathrm{h}}\left(W_{\mathrm{h}}=5 \mathrm{~J} / \mathrm{m}^{3}\right.$ and $4 \mathrm{~J} / \mathrm{m}^{3}$, respectively) to the total losses in comparison with that for the sample $S\left(W_{\mathrm{h}}=16 \mathrm{~J} / \mathrm{m}^{3}\right)$.
The difference between losses vs. maximum flux density dependences of samples 5 and 10 is negligible. We explain this effect by low contribution of the eddy current losses, which decrease with the increase of resistivity of the material (Table). Resistivity increases with the volume content of the resin in the composite material.

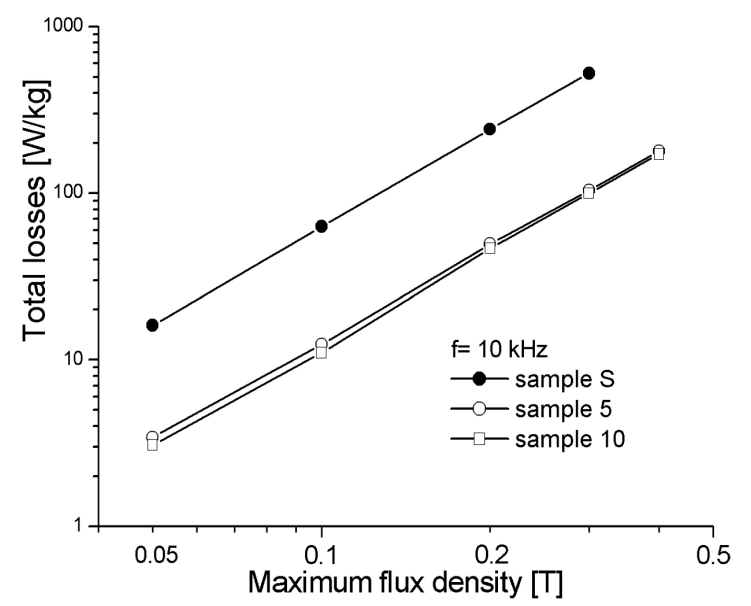

Fig. 2. Total losses as a function of maximum flux density measured for sample 5,10 and $S$ at the frequency $f=10 \mathrm{kHz}$.

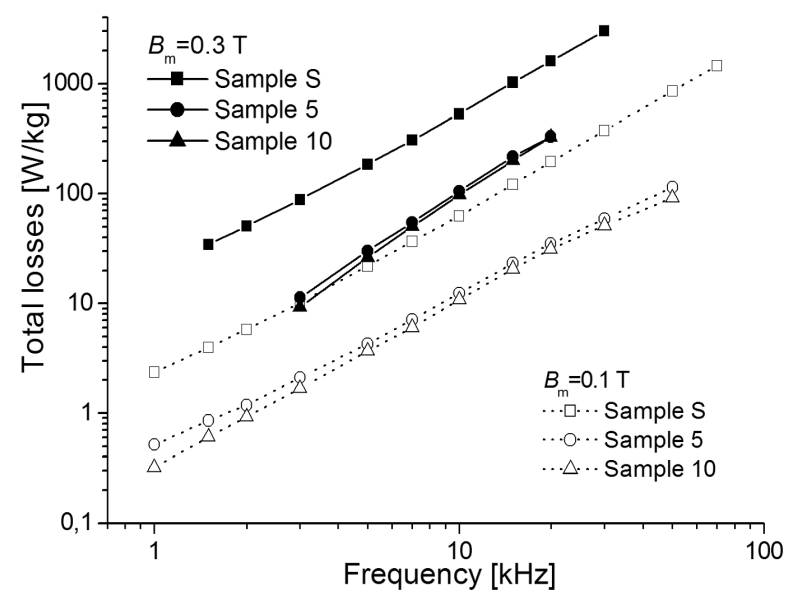

Fig. 3. Total losses $P_{\mathrm{t}}$ as a function of the frequency $f$ for samples 5, 10 and $S$ measured at maximum flux density $B_{\mathrm{m}}=0.1 \mathrm{~T}$ and $0.3 \mathrm{~T}$ in frequency range $1-100 \mathrm{kHz}$.

The total losses dependences as a function of frequency measured at the maximum flux densities of $0.1 \mathrm{~T}$ and $0.3 \mathrm{~T}$ of all samples are depicted in Fig. 3 .

The slope of total losses dependences versus frequency of samples 5 and 10 is larger than that for sample $S$ for $B_{\mathrm{m}}=0.3 \mathrm{~T}$. We assume that it is caused by a larger contribution of eddy current losses of samples 5 and 10 , due to eddy current flowing in larger cross-sections of the ferromagnetic particles (in spite of smaller specific resistivity) in contrast with sample $S[9,10]$. Experimental 
values of densities of composite material sample 5 and 10 exhibit smaller values (due to larger resin content) in comparison with the density of sample $S$ due to larger mean value of the flakes size. This leads to the creating of demagnetizing field in the material, which has a consequence in the larger tilt of the hysteresis loops [3].

\section{Conclusion}

In order to extend the possibilities of soft magnetic composite materials for application in high frequency $\mathrm{AC}$ magnetic fields we prepared and investigated two samples of Vitroperm 800-based composite material with phenolformaldehyde resin (bakelite ATM) as insulator (5 and $10 \mathrm{vol} . \%$ of resin).

We compared the total losses (measured in frequency range $1 \mathrm{kHz}$ to $100 \mathrm{kHz}$ ) of composite material with reference composite material Somaloy ${ }^{\circledR} 700$. Vitroperm based composite exhibits more than 10 times lower values of total losses (at $10 \mathrm{kHz}$ ) than Somaloy based material caused by lower contribution of hysteresis losses.

The slope of total losses dependences with frequency of Vitroperm based samples is slightly larger than for reference material, which is probably caused by a larger contribution of eddy current losses, due to the eddy current flowing in larger cross-sections of the Vitroperm perfectly insulated flakes in contrast with eddy current flowing in smaller cross-sections of powder particles of the reference material.

\section{Acknowledgments}

This work was realized within the frame of the project "Centre of Excellence of Advanced Materials with Nanoand Submicron-Structure", which is supported by the Operational Program "Research and Development" financed through European Regional Development Fund,
ITMS: 26220120019. This work was also supported by the Slovak Research and Development Agency under the contract No. APVV-0490-07 MICOMAT and by the Scientific Grant Agency of the Ministry of Education of Slovak Republic and the Slovak Academy of Sciences, project No. VEGA 1/0311/10 and No. VEGA 2/ 0149/09. Special thanks to Höganäs AB Sweden for providing Somaloy ${ }^{\circledR}$ powder and to Mr. M. Vitovský, Vacuumschmelze, GmbH \& Co. KG, Germany for providing Vitroperm 800.

\section{References}

[1] T. Maeda, H. Tyoda, N. Igarashi, K. Hirose, K. Mimura, T. Nishioka, A. Ikegaya, SEI Tech. Rev. 60, 3 (2005).

[2] H. Shokrollahi, K. Janghorban, J Mater. Proc. Technol. 189, 1 (2007).

[3] B. Weidenfeller, M. Anhalt, W. Riehemann, J. Magn. Magn. Mater. 320, e382 (2008).

[4] D. Nuetzel, G. Rieger, J. Wecker, J. Petzold, M. Mueller, J. Magn. Magn. Mater. 196-197, 327 (1999).

[5] http://www.vacuumschmelze.de .

[6] Product catalog: Somaloy ${ }^{\circledR}$ Metal Powders for SMC Components, Höganäs AB, Sweden.

[7] P. Kollár, J. Füzer, R. Bureš, M. Fáberová, IEEE Trans. Magn. 46, 467 (2010).

[8] L.J. van der Pauw, Philips Techn. Rev. 20, 220 (1958).

[9] R.M. Bozorth, Ferromagnetism, 3rd ed, IEEE Press, Piscataway (NJ) 1993.

[10] T.D. Shen, U. Harms, R.B. Schwarz, Mater. Sci. Forum 386-388, 441 (2002). 